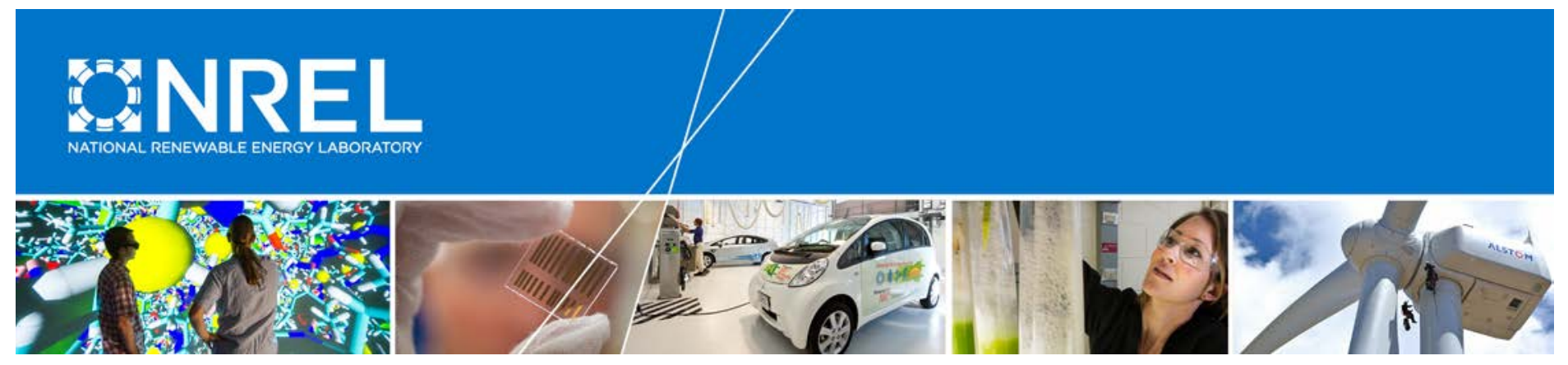

\title{
An Overview of the Automated Dispatch Controller Algorithms in the System Advisor Model (SAM)
}

Nicholas DiOrio

National Renewable Energy Laboratory

NREL is a national laboratory of the U.S. Department of Energy Office of Energy Efficiency \& Renewable Energy Operated by the Alliance for Sustainable Energy, LLC

This report is available at no cost from the National Renewable Energy Laboratory (NREL) at www.nrel.gov/publications.

Technical Report

NREL/TP-6A20-68614

November 2017

Contract No. DE-AC36-08GO28308 


\section{An Overview of the Automated Dispatch Controller Algorithms in the System Advisor Model (SAM)}

Nicholas DiOrio

National Renewable Energy Laboratory

Prepared under Task No. SETP.10304.24.01.10

NREL is a national laboratory of the U.S. Department of Energy Office of Energy Efficiency \& Renewable Energy Operated by the Alliance for Sustainable Energy, LLC

This report is available at no cost from the National Renewable Energy Laboratory (NREL) at www.nrel.gov/publications.

National Renewable Energy Laboratory 15013 Denver West Parkway Golden, CO 80401

303-275-3000 • www.nrel.gov

\section{Technical Report}

NREL/TP-6A20-68614

October 2017

Contract No. DE-AC36-08GO28308 


\section{NOTICE}

This report was prepared as an account of work sponsored by an agency of the United States government. Neither the United States government nor any agency thereof, nor any of their employees, makes any warranty, express or implied, or assumes any legal liability or responsibility for the accuracy, completeness, or usefulness of any information, apparatus, product, or process disclosed, or represents that its use would not infringe privately owned rights. Reference herein to any specific commercial product, process, or service by trade name, trademark, manufacturer, or otherwise does not necessarily constitute or imply its endorsement, recommendation, or favoring by the United States government or any agency thereof. The views and opinions of authors expressed herein do not necessarily state or reflect those of the United States government or any agency thereof.

This report is available at no cost from the National Renewable Energy Laboratory (NREL) at www.nrel.gov/publications.

Available electronically at SciTech Connect http:/www.osti.gov/scitech

Available for a processing fee to U.S. Department of Energy and its contractors, in paper, from:

U.S. Department of Energy

Office of Scientific and Technical Information

P.O. Box 62

Oak Ridge, TN 37831-0062

OSTI http://www.osti.gov

Phone: 865.576.8401

Fax: 865.576.5728

Email: reports@osti.gov

Available for sale to the public, in paper, from:

U.S. Department of Commerce

National Technical Information Service

5301 Shawnee Road

Alexandria, VA 22312

NTIS http://www.ntis.gov

Phone: 800.553 .6847 or 703.605 .6000

Fax: 703.605.6900

Email: orders@ntis.gov 


\section{Executive Summary}

Three automatic dispatch modes have been added to the battery model within the System Advisor Model, version 2017.1.17. These controllers have been developed to automatically perform peak shaving, providing users with a way to see the benefit of reduced demand charges without manually programming a complicated dispatch control. A flexible input option allows more advanced interaction with the automated controller. This document describes the algorithms in detail and presents brief results on its use and limitations. 


\section{Table of Contents}

Executive Summary ............................................................................................................... iv

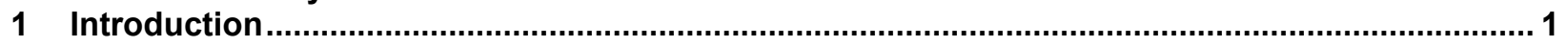

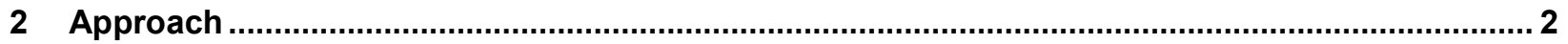

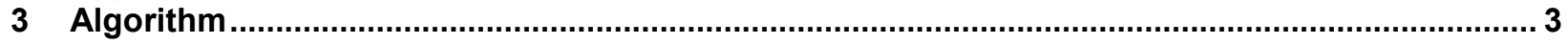

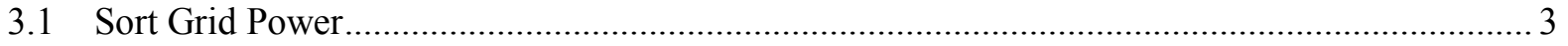

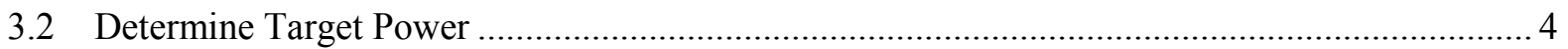

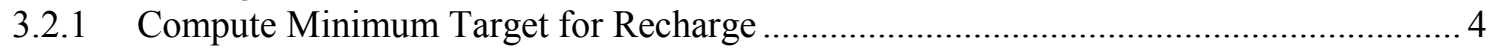

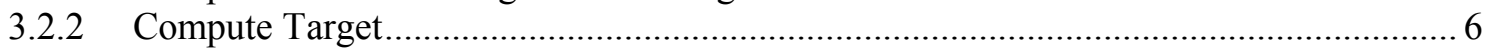

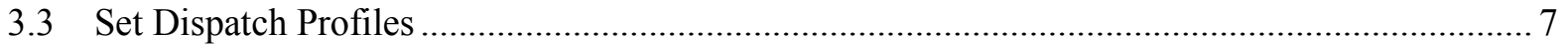

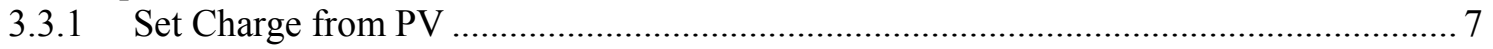

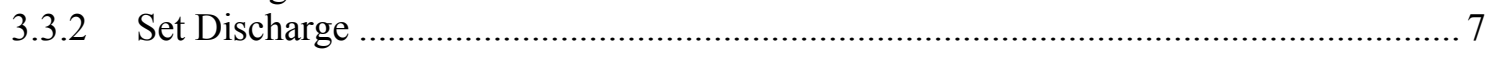

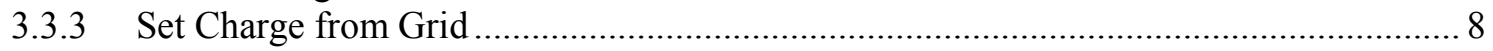

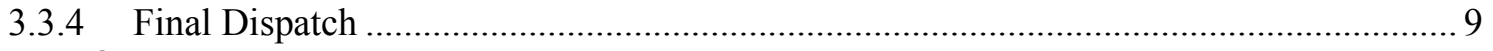

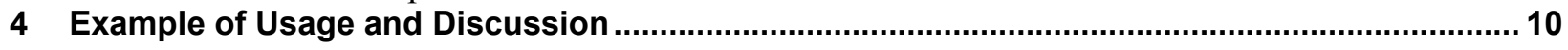

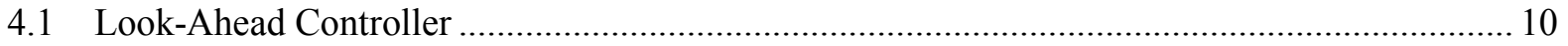

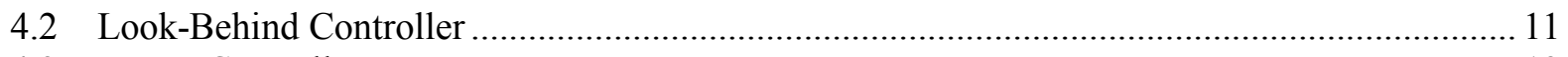

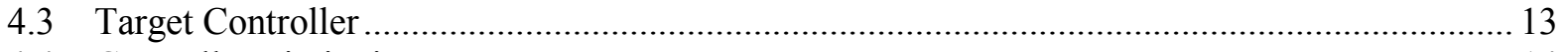

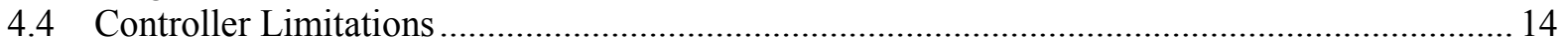

4.4.1 Peak Shaving Based on Peak Power Rather than Cost................................................ 14

4.4.2 Lack of Ability to Simultaneously Target Multiple Value Streams .............................. 15

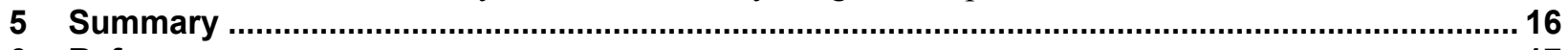

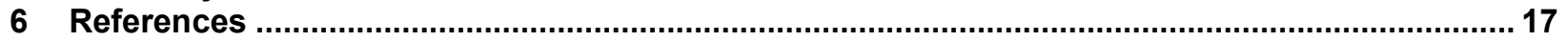

\section{List of Figures}

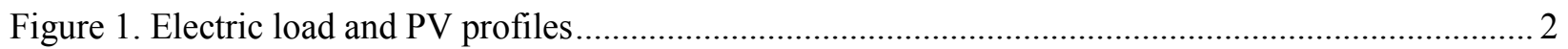

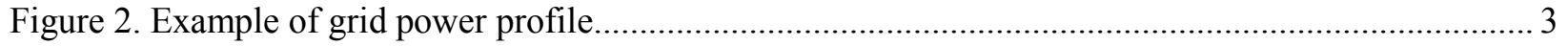

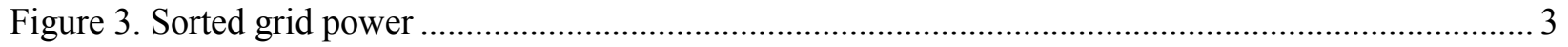

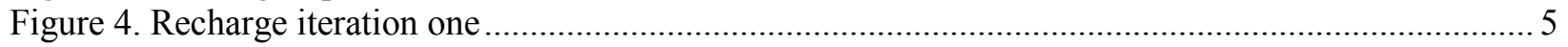

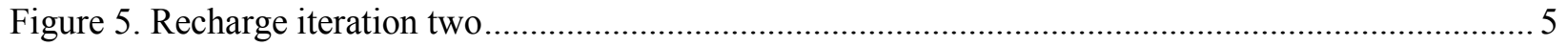

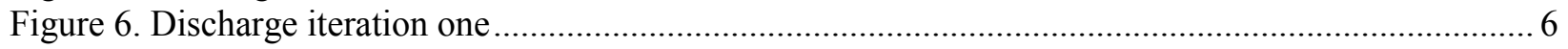

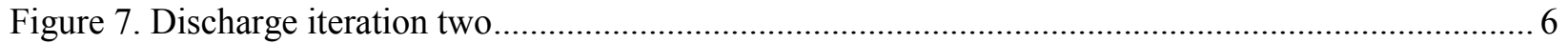

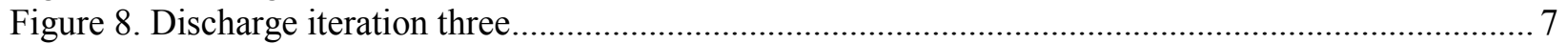

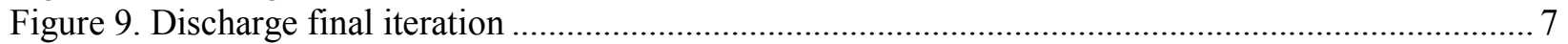

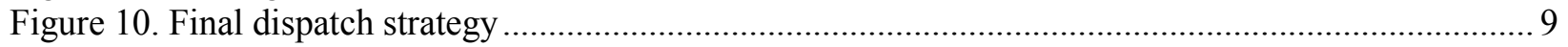

Figure 11. Look-ahead controller - power to load........................................................................... 10

Figure 12. Look-ahead controller - demand charges with and without system....................................... 11

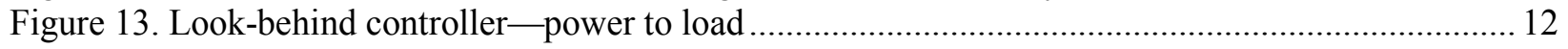

Figure 14. Look-behind controller-demand charges with and without system ................................... 12

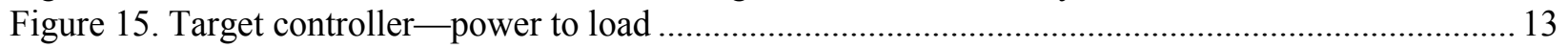

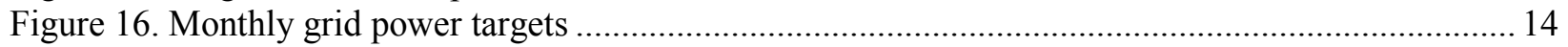

\section{List of Tables}

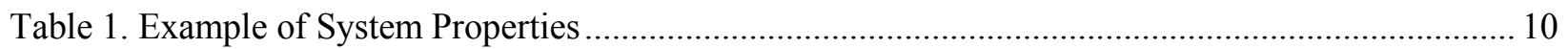

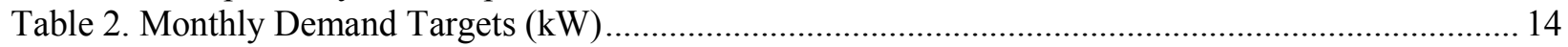




\section{Introduction}

The NREL System Advisor Model (SAM) [1] is a simulation tool linking technical performance models to detailed financial models to predict the economic performance of renewable energy systems. The tool has a photovoltaic (PV) model that can be coupled with energy storage. The basic energy storage model and dispatch capability (particularly for energy arbitrage) has been previously described in detail and compared to experimental data [2]. As an addition to the modeling capabilities described in that work, more advanced automated dispatch capabilities were added to the model with the goal of reducing peak electric demand. Peak demand reduction is one of the main value streams for behind-the-meter storage. Other potential value streams include co-optimizing energy arbitrage and peak demand reduction and performing ancillary services; however, to capture these value streams would require additional dispatch algorithms to be developed. An economic case study was done to illustrate the analysis options and potential financial benefit to installing PV-coupled storage systems in select markets [3]. The description of that work, which is described in this report details the automated dispatch algorithms developed for SAM to provide interested users details on the methods that SAM uses.

Other NREL tools perform battery modeling and dispatch with different objectives and usecases. REopt [4] formulates a mixed-integer program to solve for the lowest lifecycle cost of a site given the load profile, utility rate tariff, and technology costs. The program solves for the cost-optimal mix of technologies and their associated operation which minimize the costs to the site over the period of interest. The BLAST tool performs optimal peak load reduction for energy storage systems [5].

The dispatch algorithm in SAM varies significantly from the approaches taken in these models. Instead of performing a cost-based optimization, SAM provides options that provide automated but suboptimal dispatch to achieve specified goals. Reasons for taking this approach includebut not limited to - the consideration that SAM is a public, commercial grade tool and must be accessible to users of varying technical ability and SAM is free and unable to incorporate features requiring a paid license from other software packages. Despite these restrictions, the algorithm outlined in this work has shown significant promise for analyzing common solar plus storage scenarios [3]. The work described in this report is applicable to SAM version 2017.1.17 and newer. Over time, the algorithms are improved based upon further research and user feedback. SAM's algorithms and interface are open-source. [6] 


\section{Approach}

To automatically dispatch a battery in the presence of a photovoltaic system, some knowledge of the electricity load profile and weather must be present in the model so that a prediction of necessary grid power can be made.

Figure 1 illustrates a residential load and photovoltaic power production for the first day of January.

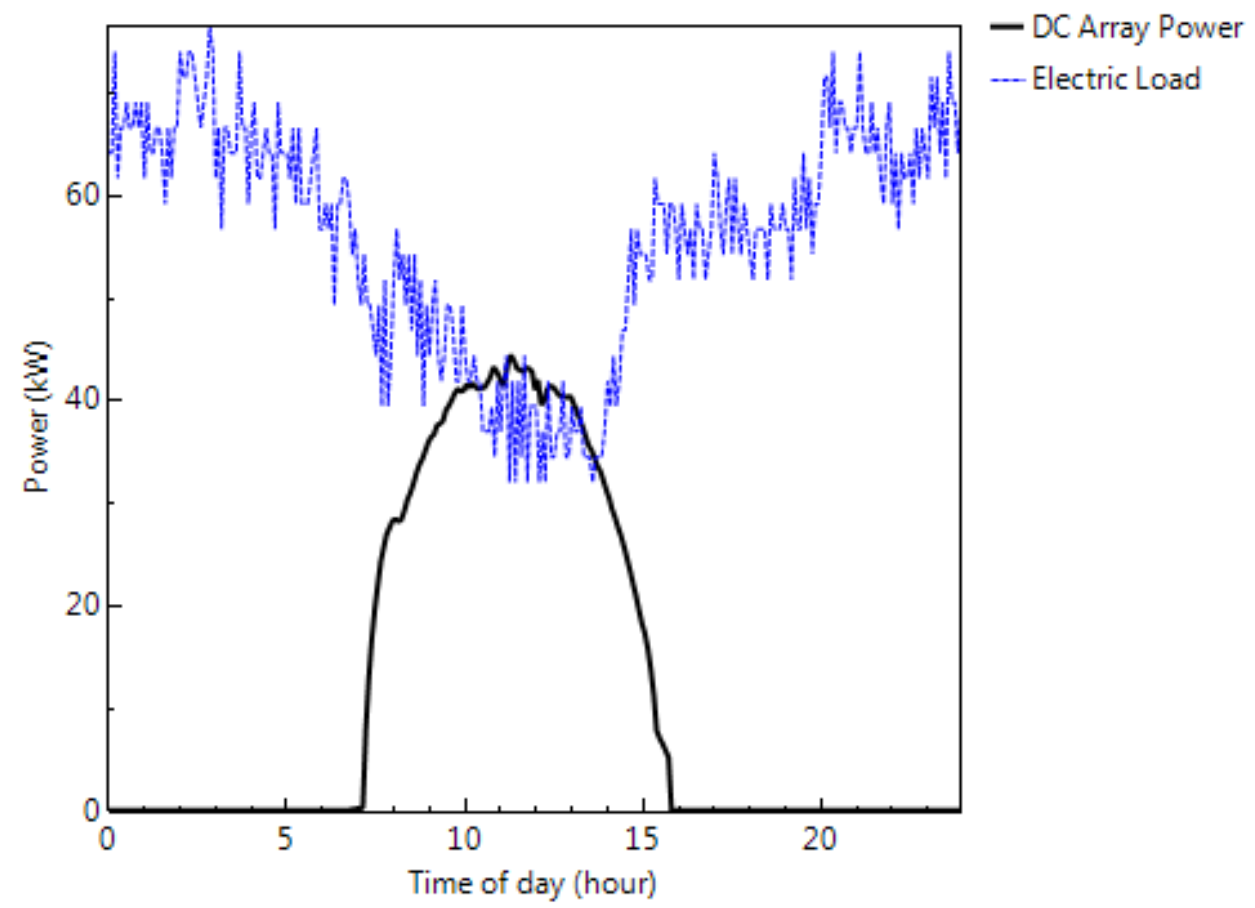

Figure 1. Electric load and PV profiles

Using the load and PV information and assuming no battery system is present, it is possible to compute the grid power required at any time using Eq. (2.1).

$$
P_{\text {grid }}=P_{\text {load }}-P_{p v}
$$

Where it is assumed that positive grid power implies power being bought from the grid to serve the load, whereas negative grid power assumes excess power being sold to the grid. By understanding the interplay of the electric load and available PV power, necessary insight is gained toward effective use of a battery to reduce grid power purchases.

While using the automated controller, SAM runs a simulation to compute the grid power required over every time step. Every day during the year, the battery dispatch is programmed by using 24 hours of data using one of two options. The user may either choose to use either a perfect look-ahead forecast (which SAM obtains from the input data) or the previous 24-hour profile. With this forecast, the dispatch algorithm programs the controller. Internally, the model tracks the current monthly peak demand to ensure the battery does not aggressively discharge to shave a daily peak that is below the current monthly peak. 


\section{Algorithm}

The automated dispatch algorithm is called at the beginning of a new 24-hour period throughout a simulation and is flexible enough to handle hourly or sub hourly time steps. The algorithm example in this section will use the grid power profile seen in Figure 2.

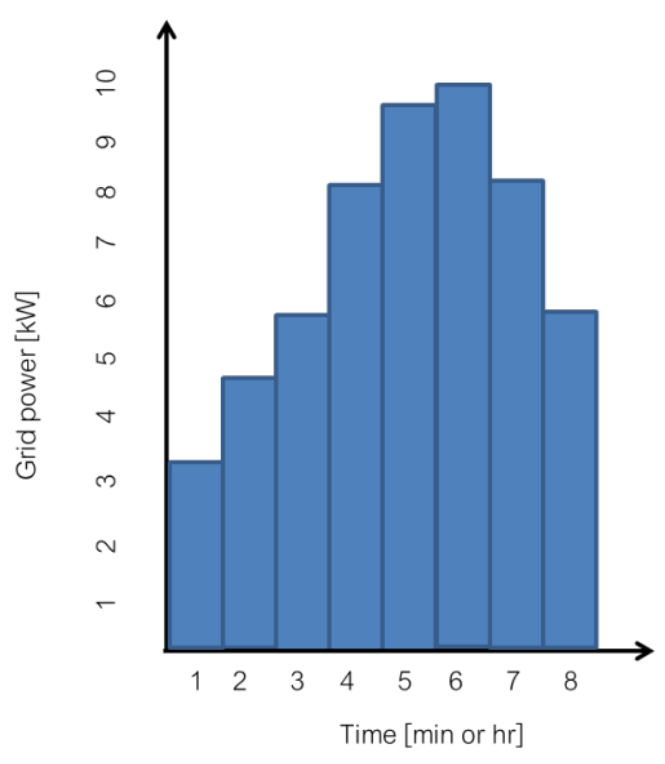

Figure 2. Example of grid power profile

\subsection{Sort Grid Power}

The first step in the automated dispatch algorithm is to compute the grid power over the next 24 hours according to Eq. (2.1). Once this calculation is computed, the powers are sorted from highest to lowest. The hour and step within the hour are also sorted to preserve information about the time to which each grid power corresponds. The results of this step are seen in Figure 3.

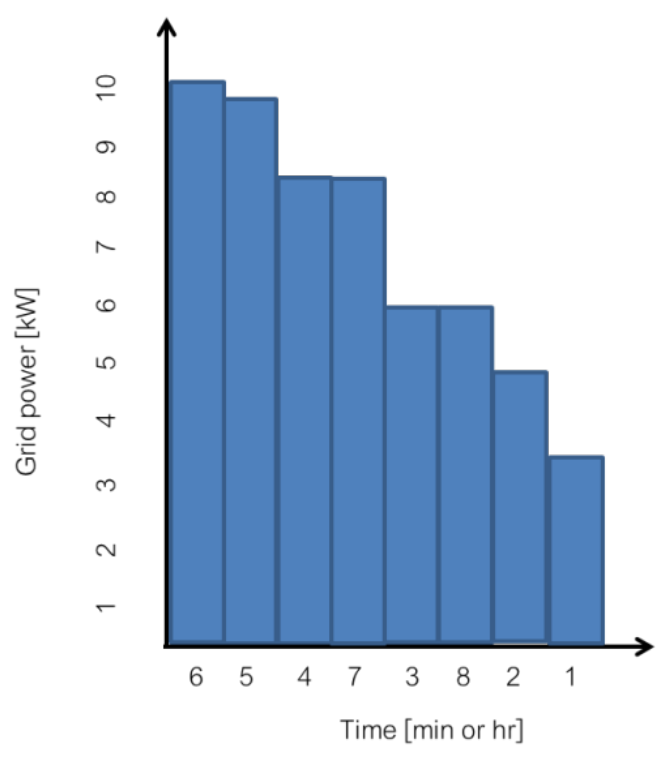

Figure 3. Sorted grid power 


\subsection{Determine Target Power}

To reduce the peak demand over the 24 hours, a target power to shave to must be determined. The target power is defined as the maximum desired power level purchased from the grid. This target power will ideally be as low as possible but must account for the limitations of the battery capacity and the power usage profile. SAM can compute the target power, or the user may input a time series array of target powers in kilowatts $(\mathrm{kW})$, though the input values are not guaranteed to be satisfied. Rather, the controller will attempt to match the input profile within the limits of other constraints, including the battery state-of-charge and current throughput constraints. The algorithm that SAM uses to calculate the target power will be described in detail.

It is assumed that the energy in kilowatt-hours $(\mathrm{kWh})$ that can be extracted from the battery over a 24-hour period is computed for lithium ion and vanadium redox flow batteries as in:

$$
E_{\max }=V q_{\max }\left(S O C_{\max }-S O C_{\min }\right) * 0.001
$$

Where $V$ is the battery voltage at the beginning of the 24-hour period, $q_{\max }$ is the maximum battery charge in Amp-hours (Ah), $S O C_{\max }$ is the user-specified maximum state-of-charge, and $S O C_{\min }$ is the user-specified minimum state-of-charge, expressed as percentages. The 0.001 factor converts from Wh to $\mathrm{kWh}$. Using this energy, the algorithm proceeds to compute how much power can be shaved. For lead-acid batteries, the maximum energy is computed using the available energy rather than maximum theoretical as:

$$
E_{\text {max }}=V q_{\text {avail }}\left(S O C_{\max }-S O C_{\min }\right) * 0.001
$$

This is done because the kinetic response of lead-acid battery capacity differs from that of lithium-ion and flow-battery chemistries, with lead-acid capacity typically being modeled as a combination of bound and available capacity. [7]

\subsubsection{Compute Minimum Target for Recharge}

The algorithm begins by computing the target power that will allow the battery to charge to the maximum energy in Equation (3.1) over the day. This is accomplished by looping over the sorted grid powers from smallest to highest and computing how much energy could be charged by setting the target power to that value. The energy accumulates as the grid power target is increased until it is determined that the maximum energy could be recharged from the grid over the day without exceeding the maximum power. 


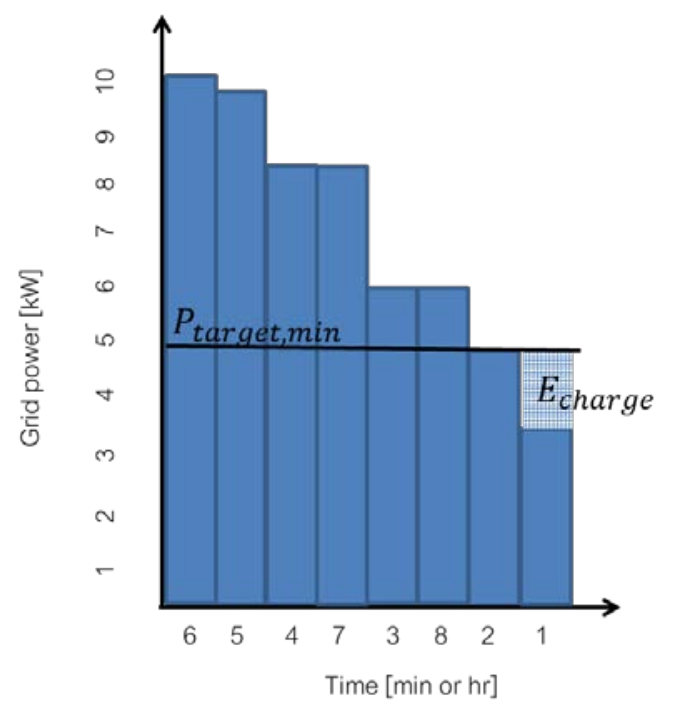

Figure 4. Recharge iteration one

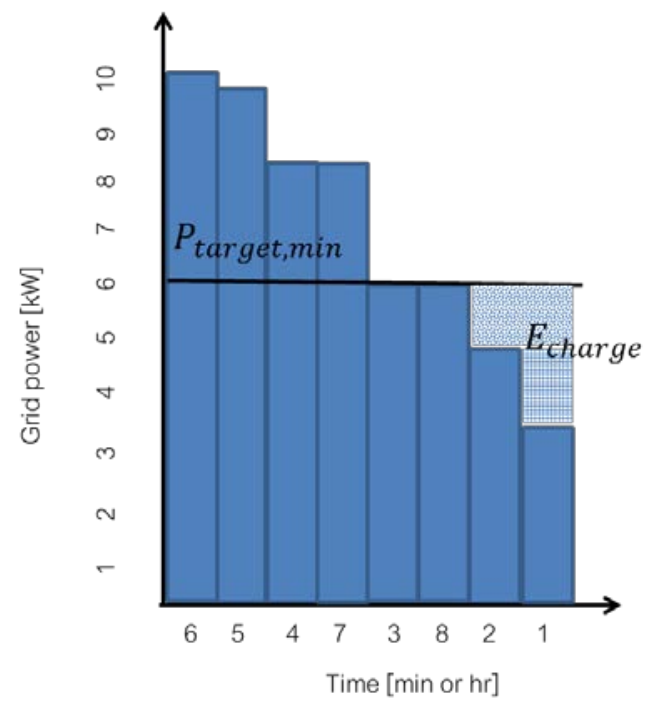

Figure 5. Recharge iteration two

The process is illustrated in Figure 4 and Figure 5. In Figure 4, the target power has been set to $5 \mathrm{~kW}$, which would allow an additional $1.5 \mathrm{~kW}$ of power to be diverted to charging the battery during iteration one. In iteration two, the power target is increased to $6 \mathrm{~kW}$, allowing an additional $1 \mathrm{~kW}$ of power for charging in iteration one, and $1 \mathrm{~kW}$ of power for charging in iteration two. The process of raising the power target increases until sufficient energy is available to charge the battery. If the target increases to the maximum target without enough energy to recharge the battery, no peak shaving is done for that day. No special consideration is given to times before or after the peak, and the battery does not have to be full at the end of the day. The only requirement is that the battery can receive the total energy charge throughout the period. 


\subsubsection{Compute Target}

The target power is calculated in a similar manner as the minimum target power. Instead of looking at recharge opportunities, the algorithm considers how much the target can be reduced before exhausting the energy in the battery. The process is illustrated in Figure 6 and Figure 7.

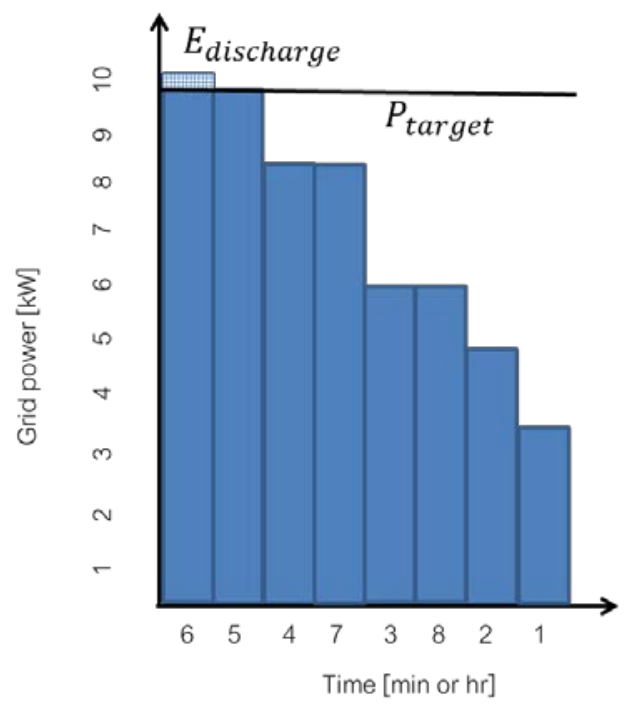

Figure 6. Discharge iteration one

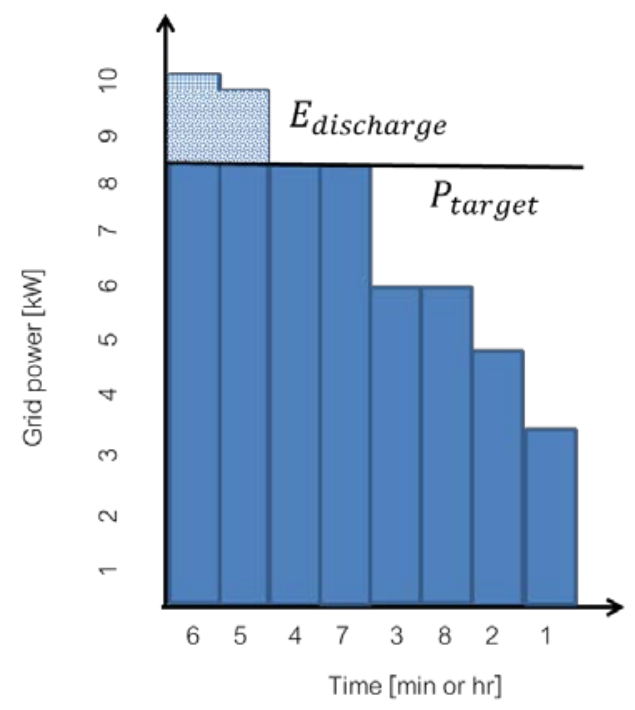

Figure 7. Discharge iteration two

In Figure 6, the target power is reduced from the highest level at period six to the level at period five. The energy required to accomplish this reduction is shown as the hatched area. Provided this energy is less than the value calculated in Eq. (3.1), the algorithm proceeds to the next power level, shown in Figure 7, where another hatched area illustrates the additional energy required. If the next power target would require more energy from the battery than is possible, the target would be bumped up until the energy required to discharge equals the maximum energy in the battery. 
Figure 8 illustrates an iteration that reduces the target to the next power level but to where the energy required from the battery would exceed the maximum energy of the battery. Figure 9 shows the algorithm correcting for this by increasing the target power until the energy required to discharge is equal to the maximum energy.

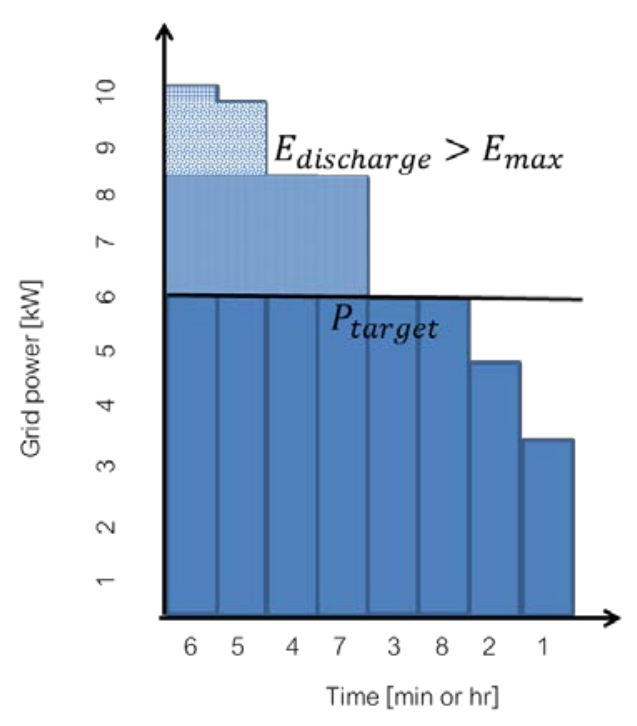

Figure 8. Discharge iteration three

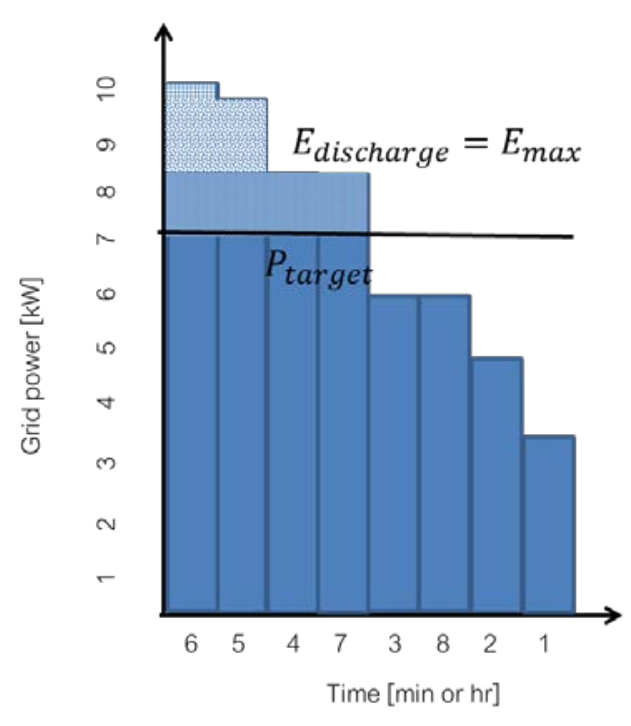

Figure 9. Discharge final iteration

The computed target is increased by $3 \%$ to account for any differences in voltage that may contribute to more energy being discharged than anticipated. The target power calculated is compared to the minimum target power required to recharge the battery. If the target power is less than the minimum required, the target is made equal to the minimum to allow sufficient recharging of the battery. Finally, the target power is checked against the current maximum target power for the month, which is an internally stored value that is calculated every day. If the computed target power for the next 24 hours is less than the maximum target power for the month, the target is set to the max of the month, as additional demand charge reduction will serve no purpose in further reducing the monthly demand charge.

\subsection{Set Dispatch Profiles}

Once the target power has been computed, the dispatch controller is programmed.

\subsubsection{Set Charge from PV}

The controller is programmed to always charge the battery from excess PV power. The excess $\mathrm{PV}$ power is accounted for in the grid power calculation when programming the battery discharge.

\subsubsection{Set Discharge}

The battery controller in SAM is programmed on a percent-energy basis; that is, in addition to specifying that the battery is allowed to charge in one period, what percent of energy the battery is allowed to discharge over each time-step within the period is also specified. This mechanism is described in detail in [2]. 
A loop over all time steps in the 24-hour period is done, and the energy required to discharge to meet the power target is computed as in Equation (3.3).

$$
E_{\text {required discharge }}=\left[P_{\text {grid }}-P_{\text {target }}\right] \Delta t
$$

If this quantity is greater than zero, energy must be discharged from the battery. The percent to discharge from the battery over the time-step is computed in Equation (3.4).

$$
\text { percent discharge }=100 * \frac{E_{\text {required discharge }}}{E_{\max }}
$$

The amount of resultant power that the battery discharges is assumed to be within the discharge limits of the battery. That is, it is assumed the battery C-rate of discharge is greater than or equal to the resultant discharge and that the battery inverter or shared inverter (in the case of a DCconnected system) has enough capacity to accept the full amount of battery power. If the resultant power violates these constraints, the power will later be limited to meet the constraints.

\subsubsection{Set Charge from Grid}

Finally, the charge profile from the grid is set. In a similar manner as the dispatch, percentenergies must be computed to program the controller. The battery is set to only charge from the grid if sufficient PV energy is not available to charge the battery over the course of the day. A loop over all times is done, and the energy required to charge is computed as:

$$
E_{\text {required gridcharge }}=\left[P_{\text {target }}-P_{\text {grid }}\right] \Delta t
$$

The percent to charge from the grid over the time period is computed as:

$$
\text { percent gridcharge }=100 * \frac{E_{\text {required gridcharge }}}{E_{\max }}
$$

Again, the resultant power is assumed to be within operational power range of the battery and within the range of the connected power electronics. Otherwise, the power will later be limited by the user-specified constraints. 


\subsubsection{Final Dispatch}

Figure 10 shows what the final strategy might look like after the algorithm computes the grid target, programming the charge and discharge, depending on the battery capacity and grid target. The battery will discharge during hours when the electric load is greater than the grid target and charge during hours when the electric load is lower than the grid target.

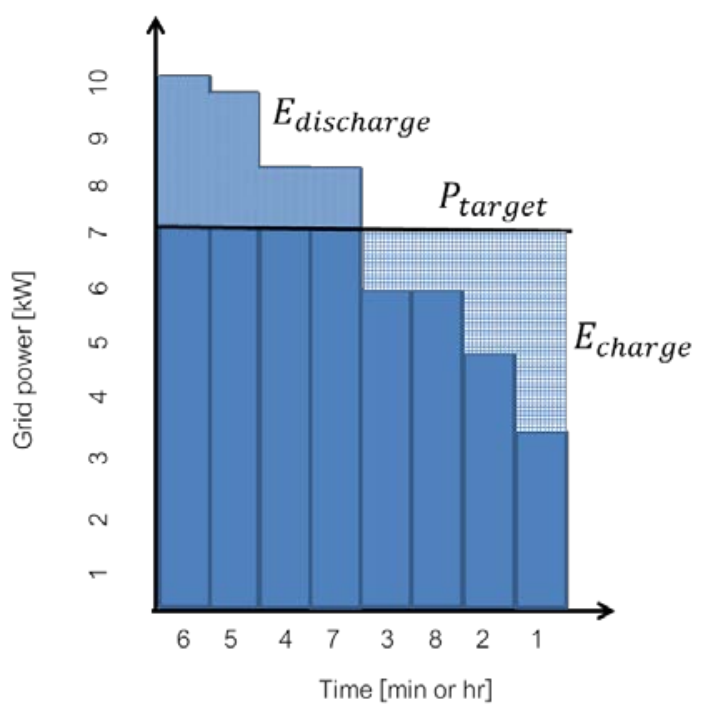

Figure 10. Final dispatch strategy 


\section{Example of Usage and Discussion}

To illustrate the use of the automatic controller, an example of a system will be considered with the properties shown in Table 1. No detailed financial analysis will be considered, as this has been done in previous work [3]; however, examples of demand charge reduction will be shown. The example is run with five-minute load and weather data from a site near Los Angeles, California.

Table 1. Example of System Properties

\begin{tabular}{l|l}
\hline Property & Value \\
\hline PV nameplate capacity & $0 \mathrm{~kW}$ \\
\hline Peak load & $99 \mathrm{~kW}$ \\
\hline Utility rate structure & SCE TOU-GS-2 Option B \\
\hline Battery type & Lithium ion-NMC \\
\hline Battery capacity & $90 \mathrm{kWh} / 45 \mathrm{~kW}$ \\
\hline Minimum state-of-charge & $15 \%$ \\
\hline Maximum state-of-charge & $95 \%$ \\
\hline
\end{tabular}

The controllers are run for one day.

\subsection{Look-Ahead Controller}

Figure 11 illustrates the reduction in grid power resulting from the look-ahead controller. In the morning and afternoon, the battery reduces the grid power by about $15 \mathrm{~kW}$ as the battery power fluctuates to maintain that grid power requirement. Figure 12 shows the resulting reduction in demand charges from month to month. It is apparent that great demand charge reduction can be accomplished with this controller for this utility rate strategy, particularly in summer months.

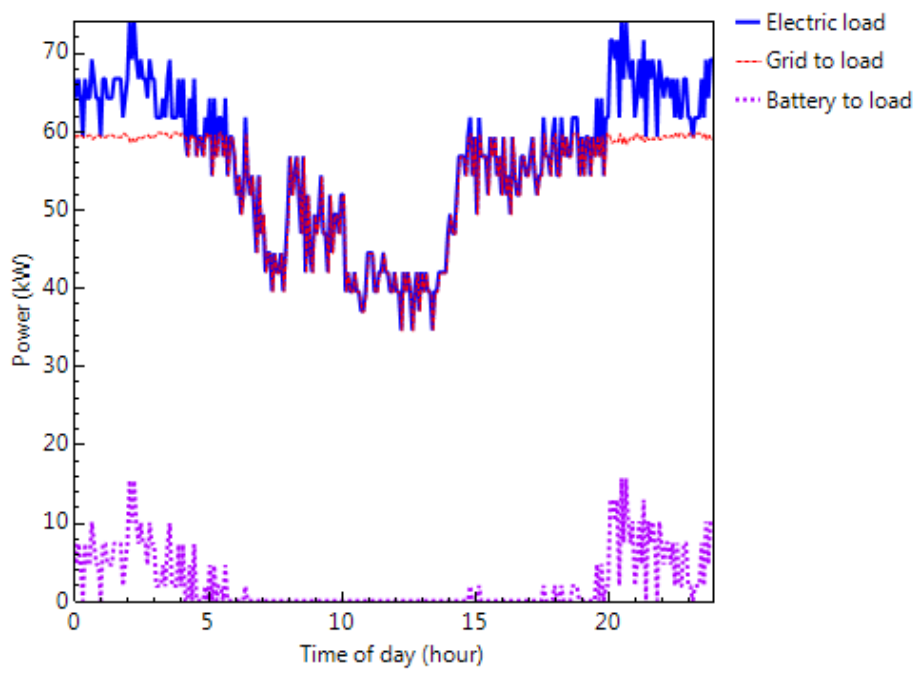

Figure 11. Look-ahead controller-power to load 


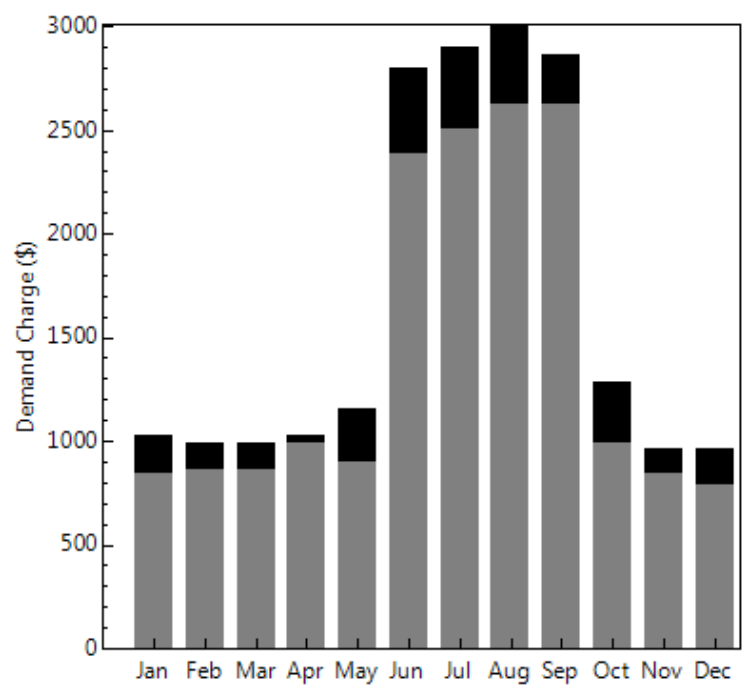

No System

With System

Figure 12. Look-ahead controller-demand charges with and without system

It is clear that even a simple algorithm seeking to naively reduce the grid power purchased over a 24-hour period can yield a great economic benefit. The algorithm accomplishes significant demand charge reduction in cases where the peak power is coincident with the highest time-ofuse demand charges. The battery operates in a manner as to reduce unnecessary cycling of the battery, by accounting for the monthly peak demand and only discharging during days when the monthly peak is in danger of increasing.

\subsection{Look-Behind Controller}

The look-behind controller assumes the load and PV production yesterday will correspond to the current 24-hour profile. This assumption is made to consider what may happen in a realistic battery control that must make decisions about dispatching a battery without perfect knowledge of the load and PV production in the future. While no real controller is likely to have a full 24-hour look-behind, this algorithm is meant to capture a worst-case, fairly simple control strategy. 


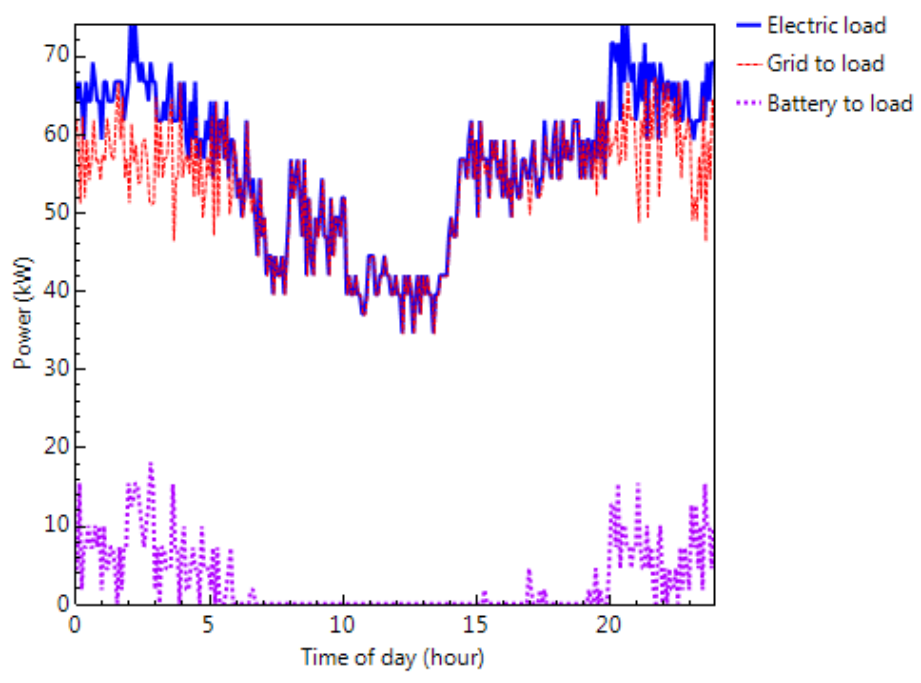

Figure 13. Look-behind controller-power to load

Figure 13 shows the power sent to the electric load for the same day as the look-ahead controller. It is apparent that using the previous 24-hours information about PV and electric load was not sufficient to generate a good dispatch strategy, leading to little peak reduction for this day. Figure 14 shows demand charges with and without the system. In this case, the look-behind controller results in worse demand charges than without a system, illustrating the potential perils of using yesterday's weather and load as the basis for controlling the battery in the future. This example illustrates that the assumed forecast can make or break a battery dispatch strategy.

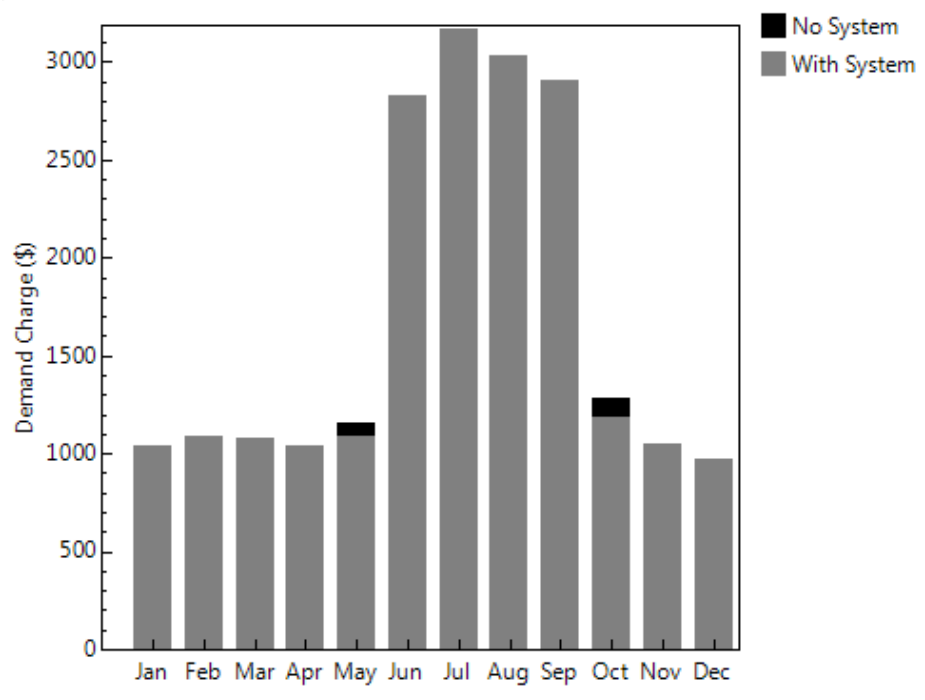

Figure 14. Look-behind controller-demand charges with and without system 


\subsection{Target Controller}

To provide the user more options on how to tailor the controller, a target power option has been implemented. This controller allows the user to input the maximum grid power for several different cases. The user can enter a single target power for the year, one target for each month, or one target for each time-step in the year. The look-ahead controller then uses the programmed target power instead of calculating its own. There are potential applications that are ideally served by this type of controller. For instance, if a microgrid is being served by a line restricted to $80 \mathrm{~kW}$ of power, but the electric demand is beginning to experience days above this line capacity, the grid owner may be interested in evaluating battery installation versus the cost of installing additional or upgrading lines.

Such a control would allow them to set the target power to $80 \mathrm{~kW}$ every time step and then consider how large a battery system would be required to ensure the grid requirement was always less than $80 \mathrm{~kW}$. Figure 15 illustrates this scenario.

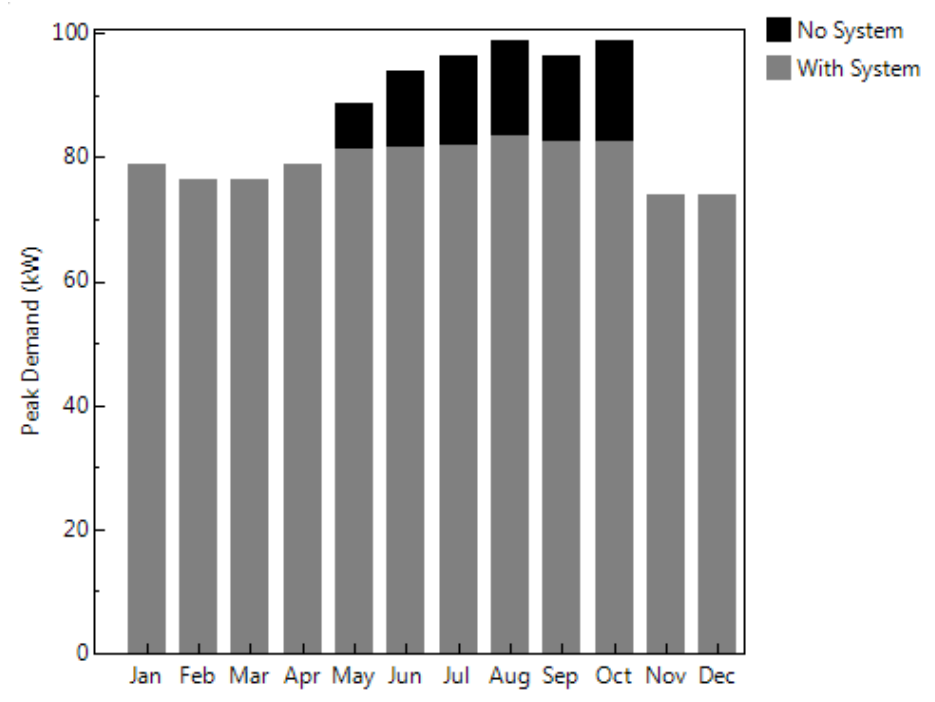

Figure 15. Target controller-power to load

There are days throughout the year when the electric load is greater than $80 \mathrm{~kW}$ and the battery reduces the power. Of note is that the controller does not perfectly reduce the load to $80 \mathrm{~kW}$, because of differences in battery voltage and temperature when the dispatch is calculated and when it is applied.

In another use case, a user may have calculated the monthly demands they want the system to achieve. A user may have used another dispatch optimization tool to compute the monthly demand targets in Table 2. 
Table 2. Monthly Demand Targets (kW)

\begin{tabular}{|c|c|c|c|c|c|}
\hline January & February & March & April & May & June \\
\hline 67 & 67 & 67 & 77 & 69 & 73 \\
\hline July & August & September & October & November & December \\
\hline 78 & 79 & 81 & 77 & 65 & 61 \\
\hline
\end{tabular}

When a user programs these targets exactly, the model operates with a more conservative target being set by a couple of percent. This is done because the voltage used in Eq. (3.1) is the voltage at the beginning of the timestep, and will change over the next 24 -hour period as the battery state changes, resulting in slightly more or less energy being discharged. When this is done, the algorithm results in consistent grid-power reduction as shown in Figure 16.

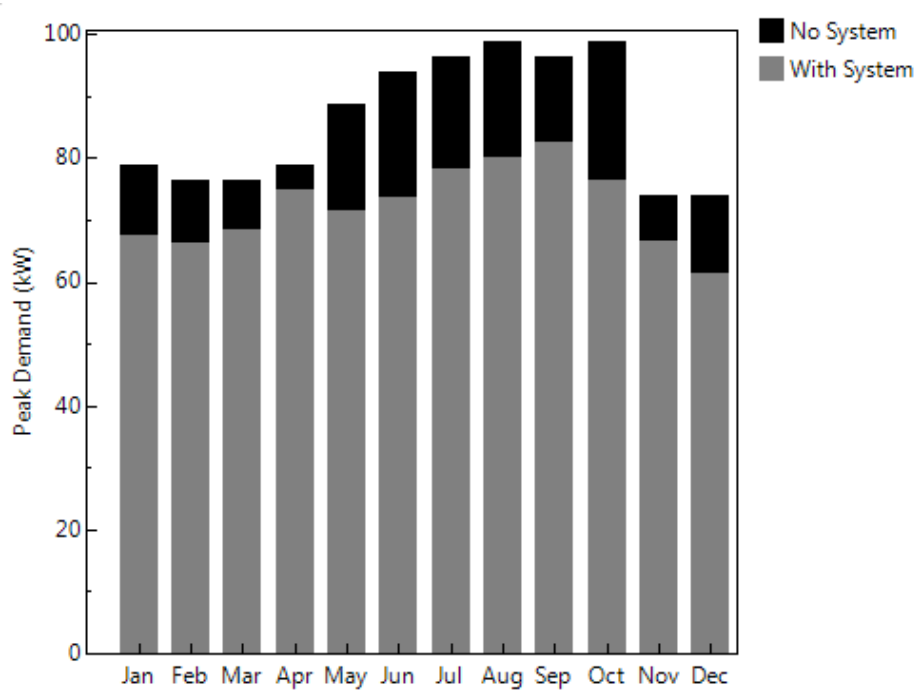

Figure 16. Monthly grid power targets

Because target power can be entered for each time step, high granularity analysis can be conducted if desired. It is also worth noting that if the battery is insufficiently sized to shave to the target grid power, it will be unable to accomplish the dispatch. The dispatch will always seek to satisfy state-of-charge, current throughput, and cycling requirements before meeting the target power. In this case, the battery system evaluated is sufficient to offset the grid power required.

\subsection{Controller Limitations}

The heuristic control algorithms developed for SAM have some notable limitations on their use and performance.

\subsubsection{Peak Shaving Based on Peak Power Rather than Cost}

The algorithms do not currently take any information about cost into consideration but rather develop dispatch around the assumption that peak costs will be coincident with peak consumption hours. While this is often a good assumption, it is not true for every location or every load profile type. If a building owner sees peak demand in the middle of the night but is on a utility rate where the peak demand charges are in the late afternoon, performing peak shaving 
with the heuristic algorithm described here will lead to mixed results at best. The controller also operates on weekends, which often have lower demand rates than weekdays. In the event that a business experiences most of its demand on weekends but operates on a time-of-use demand rate with high weekly demand charges and no weekend charges, the controller will not result in a valuable peak demand charge reduction.

\subsubsection{Lack of Ability to Simultaneously Target Multiple Value Streams}

Another restriction in the controller is that each dispatch strategy is targeted to one value stream (i.e., either reducing demand charges or reducing energy charges). For instance, the peak shaving controllers seek to reduce the electric demand over the course of 24 hours (and subsequently, reduce monthly demand charges). While doing this, the controller may also inadvertently reduce energy charges as well (particularly if peak energy charges are coincident with peak demand times), but no consideration of energy costs are taken into account. A user can manually schedule the battery to charge and discharge to perform energy arbitrage (buying energy at low cost and selling at high cost), but this method of dispatch is ill suited to demand charge reduction. With advanced use of the controller, it is possible that a user could tailor the gridpower target to simultaneously perform demand charge reduction and energy charge reduction, but computing the grid power target for every time step would have to be done external to SAM. 


\section{Summary}

Three automatic dispatch modes have been added to the battery model within the System Advisor Model (SAM). The modes provide users the option to evaluate different strategies for peak-shaving and charge control in a way that does not require detailed programming. For advanced users, the target power controller provides a way to input detailed information and further tailor battery dispatch to meet specific power goals. While these heuristic algorithms do not do any optimization around the cost of energy and power, they do provide a way to evaluate the value of peak shaving for demand charge reduction for peak demand that is coincident with high time-of-use demand charges. The importance of accurately forecasting the electric load and PV production is critical to obtaining a dispatch strategy that reduces peak demand without prematurely exhausting the battery capacity. 


\section{References}

[1] National Renewable Energy Laboratory, "System Advisor Model," https://sam.nrel.gov.

[2] Nicholas DiOrio, Aron Dobos, Steven Janzou, Austin Nelson, and Blake Lundstrom. 2015. Technoeconomic Modeling of Battery Energy Storage in SAM. Golden, CO: National Renewable Energy Laboratory. NREL/TP-6A20-64641. https://www.nrel.gov/docs/fy15osti/64641.pdf.

[3] Nicholas DiOrio, Aron Dobos, and Steven Janzou. 2015. Economic Analysis Case Studies of Battery Energy Storage with SAM. Golden, CO: National Renewable Energy Laboratory. NREL/TP-6A20-64987. https://www.nrel.gov/docs/fy16osti/64987.pdf.

[4] Dylan Cutler, Dan Olis, Emma Elgqvist, Xiangkun Li, Nick Laws, Nick DiOrio, Andy Walker and Kate Anderson. 2017. REopt: A Platform for Energy System Integration and Optimization Golden, CO: National Renewable Energy Laboratory. NREL/TP-7A40-70022. https://www.nrel.gov/docs/fy17osti/70022.pdf

[5] J. Neubauer and M. Simpson. 2015. Deployment of Behind-The-Meter Storage for Demand Charge Reduction. Golden, CO: National Renewable Energy Laboratory. NREL/TP-540063162. https://www.nrel.gov/docs/fy15osti/63162.pdf.

[6] National Renewable Energy Laboratory, "SAM open source" https://github.com/NREL/SAM

[7] James Manwell and Jon McGowan. 1993. Lead Acid Battery Storage Model for Hybrid Energy Systems., in Solar Energy vol. 50, No. 5 pp 399-405 (1993) 